\title{
Review Article \\ The Evolution of Prognostic Factors in Multiple Myeloma
}

\author{
Amr Hanbali, Mona Hassanein, Walid Rasheed, Mahmoud Aljurf, and Fahad Alsharif
}

King Faisal Specialist Hospital and Research Center, Riyadh, Saudi Arabia

Correspondence should be addressed to Amr Hanbali; ahanbali@kfshrc.edu.sa

Received 17 October 2016; Revised 22 January 2017; Accepted 5 February 2017; Published 21 February 2017

Academic Editor: David H. Vesole

Copyright (C) 2017 Amr Hanbali et al. This is an open access article distributed under the Creative Commons Attribution License, which permits unrestricted use, distribution, and reproduction in any medium, provided the original work is properly cited.

\begin{abstract}
Multiple myeloma (MM) is a heterogeneous hematologic malignancy involving the proliferation of plasma cells derived by different genetic events contributing to the development, progression, and prognosis of this disease. Despite improvement in treatment strategies of $\mathrm{MM}$ over the last decade, the disease remains incurable. All efforts are currently focused on understanding the prognostic markers of the disease hoping to incorporate the new therapeutic modalities to convert the disease into curable one. We present this comprehensive review to summarize the current standard prognostic markers used in MM along with novel techniques that are still in development and highlight their implications in current clinical practice.
\end{abstract}

\section{Introduction}

Multiple myeloma (MM) is a heterogeneous hematologic malignancy involving the proliferation of plasma cells derived by different genetic events contributing to the development, progression, and prognosis of this disease. Despite improvement in treatment strategies of MM over the last decade, the disease remains incurable in most cases, although in recent years overall survival of patients has been significantly increased. All current efforts are focused on the development of novel diagnostic and therapeutic modalities hoping to convert the disease into a curable one. Over the last 15 years, new techniques in prognostic markers and novel imaging modalities became available.

Risk stratification of MM is essential for understanding the prognosis and modifications of therapeutic modalities. Patients with MM who are stratified as high risk, such as those with 17 p13 deletion, generally have poor outcome with current treatment strategies and all efforts currently are focused on establishing alternative strategies for management of such patients. For the low-risk patients, they have at least 50\% chance of surviving more than 10 years.

Our aim of this review is to summarize the current standard prognostic markers used in MM along with novel techniques that are still in development and highlight their implications in current clinical practice.
The prognostic factors of MM will be divided into 4 major sections:

(1) Risk Stratification, which includes Staging of MM, Plasma Cell Labeling index (PCLI), Cytogenetics and Gene Expression Profiling (GEP)

(2) Monitoring of Response Tools, which includes Serum-Free Light Chain Assay, serum Heavy/Light Chain (HLC) Assay (Hevylite ${ }^{\mathrm{TM}}$ ), and Advanced Imaging Modalities.

(3) Minimal Residual Disease (MRD) Monitoring Methods, which includes Circulating Plasma Cells, MRD Monitoring in General, and the Value of Depth of Response

(4) Novel Prognostic Markers

\section{Risk Stratification}

2.1. Staging of $M M$. Determining the prognosis in $M M$ requires the knowledge of tumor and host factors. Work on stratifying MM into different stages started in the 1960s and early 1970 s when a number of clinical and laboratory parameters were identified, including hemoglobin level, serum calcium, serum creatinine, and severity of bone lesions $[1,2]$. In 1975, Durie and Salmon [3] developed a Durie-Salmon Staging (DS) system as a prognostic model using the following 
parameters that predicted myeloma cell tumor burden: hemoglobin level, serum calcium level, the number of bone lesions on bone X-ray, and the level and type of monoclonal protein.

Durie-Salmon staging system for multiple myeloma (see $[3,4])$ is as follows.

Stage I. Low cell mass is $<0.6 \times 10^{12}$ cells $/ \mathrm{m}^{2}$ plus all of the following:

(i) $\mathrm{Hgb}>10 \mathrm{~g} / \mathrm{dL}$

(ii) Serum IgG $<5 \mathrm{~g} / \mathrm{dL}$

(iii) Serum $\operatorname{IgA}<3 \mathrm{~g} / \mathrm{dL}$

(iv) Normal serum calcium

(v) Urine monoclonal protein excretion $<4$ g/day

(vi) No generalized lytic bone lesions.

Stage II. Intermediate cell mass is neither stage I nor stage III.

Stage III. High cell mass is $>1.2 \times 10^{12}$ cells $/ \mathrm{m}^{2}$ plus one or more of the following:

(i) $\mathrm{Hgb}<8.5 \mathrm{~g} / \mathrm{dL}$

(ii) Serum $\operatorname{IgG}>7 \mathrm{~g} / \mathrm{dL}$

(iii) Serum $\operatorname{IgA}>5 \mathrm{~g} / \mathrm{dL}$

(iv) Serum calcium $>12 \mathrm{mg} / \mathrm{dL}(3 \mu \mathrm{mol} / \mathrm{L})$

(v) Urine monoclonal protein excretion $>12 \mathrm{~g} /$ day

(vi) Advanced lytic bone lesions

Stage III is subclassified as IIIA or IIIB based on serum creatinine:

(A) Serum creatinine $<2 \mathrm{mg} / \mathrm{dL}(177 \mu \mathrm{mol} / \mathrm{L})$

(B) Serum creatinine $\geq 2 \mathrm{mg} / \mathrm{dL}$

DS system was adopted as a standard method for MM staging for many years and it became the most commonly used prognostic scheme in patients with newly diagnosed MM. The drawbacks of this system included the following: it focuses on variables correlate with myeloma mass and it does not take into account the biologic variability of the disease. Also, one of the important elements of DS system is the number of lytic lesions seen on skeletal survey, which is operator dependent. Since then, several other staging systems have been proposed using other known prognostic factors, including C-reactive protein albumin and plasma cell labeling index [5-8], but the one that gained wide acceptance was the international staging system (ISS) that was published in 2005 [4]. ISS is a simple staging system that is based on the serum beta- 2 microglobulin $(\mathrm{S} \beta 2 \mathrm{M})$ and albumin.

International staging system for myeloma (see [4]) is as follows:

Stage 1: $\beta 2 \mathrm{M}<3.5$ and $\mathrm{ALB} \geq 3.5$
Stage 2 : $A L B<3.5$ and $\beta 2 \mathrm{M}<3.5 ; \mathrm{ALB}<3.5$; or $\beta 2 \mathrm{M}$ $3.5-<5.5$

Stage 3: $\beta 2 \mathrm{M} \geq 5.5$

where $\beta 2 \mathrm{M}$ is serum $\beta 2$ microglobulin in $\mathrm{mg} / \mathrm{dL}$ and $\mathrm{ALB}$ is serum albumin in $\mathrm{g} / \mathrm{dL}$.

The ISS evolved from a statistical model focusing on survival duration [4]. The ISS is a major improvement over the DSS in that it separates patients into cohorts using easily measurable, objective, and reproducible parameters [9]. The major criticism of ISS was the lack of the use of known other prognostic markers in MM including cytogenetics abnormalities (CA) and LDH. In 2015, Palumbo et al. [10] published revised international staging system (ISS-R) which combined ISS with CA and LDH as follows.

Revised international staging system (see [10]) is as follows:

Stage I: ISS I, standard risk by FISH and normal LDH Stage II: not R-ISS I or III

Stage III: ISS III, either high risk by FISH or high LDH

where (i) high risk by FISH is presence of $\operatorname{del}(17 \mathrm{p})$ and/or translocation $\mathrm{t}(4 ; 14)$ and/or $\mathrm{t}(14 ; 16)$, (ii) standard risk by FISH is no high-risk chromosomal abnormalities, (iii) normal LDH is serum $\mathrm{LDH}<$ the upper limit of normal, and (iv) high $\mathrm{LDH}$ is serum $\mathrm{LDH}>$ the upper limit of normal.

ISS-R is proving to be a powerful prognostic staging system, but currently its use in practical practice is limited and it is used primarily for risk stratification of patients in clinical trials.

2.2. Plasma Cell Labeling Index. MM is characterized by proliferation of monoclonal plasma cells (PCs) in the bone marrow. There are certain characteristics of this proliferation that correlate with prognosis of MM, including plasma cell labeling index (PCLI), circulating plasma cells, and plasmablastic morphology.

PCLI is a measure of marrow plasma cells in S phase of the cell cycle, which provides a good estimate of the proliferative capacity of the malignant clonal plasma cells [11]. In 1993, Greipp et al. demonstrated that PCLI and B2M measured at diagnosis are independent prognostic factors in MM [12]. This was confirmed in other studies, including the study by Steensma et al., which demonstrated that high PCLI in patients with apparently stable, plateau phase MM is an adverse parameter that may predict a short time to disease progression and death [13]. Another study by Li et al. showed that PCLI was higher among patients with del (13q14), and patients with a high PCLI had a short time to disease progression [14]. Currently PCLI is rarely used because of the availability of more practical prognostic methods.

2.3. Cytogenetics. MM is a malignancy of plasma cells which develops through genetic aberrations, epigenetic changes, and the bone marrow microenvironment interaction. In the past decade, nonrandom chromosomal aberrations such as $\mathrm{t}(4 ; 14), \mathrm{t}(14 ; 16), \mathrm{t}(14 ; 20)$, amplq21, and del $17 \mathrm{p}$ have been shown to be associated with poor prognosis, and moreover, 
recent progress in genome-wide deep sequencing studies revealed mutations and intratumor subclonal heterogeneity which may explain the clinical phenotype and therapeutic resistance.

2.3.1. $t(4 ; 14)$. The prognostic significance of $t(4 ; 14)$ as detected by RT-PCR on BM and PB samples of 208 patients with $\mathrm{MM}$ and 52 patients with monoclonal gammopathy of undetermined significance (MGUS) was assessed. The results showed that the presence of this translocation is associated with poor survival $(P=0.006)$ and poor response to firstline chemotherapy $(P=0.05)$ [15]. At Mayo Clinic, in a series of 238 patients studied between 1990 and 2001, t(4;14) was determined in 153 patients, suggesting that high-dose therapy, as used to be in their practice, has minimal benefit for these patients with a median time to progression of only 8.2 months after stem cell therapy [16]. In another study, 19 patients with $\mathrm{t}(4 ; 14)$ showed a good response to vincristine, doxorubicin, and dexamethasone (VAD) induction chemotherapy or pulsed dexamethasone alone, but early progression was common before HDT, with evident resistance to alkylating agents [17]. The results after a long term follow-up of 100 cases of MM with $\mathrm{t}(4 ; 14)$, treated in IFM99 trials with tandem transplantation, revealed a heterogeneity in patients expressing $\mathrm{t}(4 ; 14)$. They usually have similar overall response rates after both induction and HDT, to those achieved in patients without $\mathrm{t}(4 ; 14)$. However, achievement of CR or VGPR after HDT in patients with $\mathrm{t}(4 ; 14)$ was a powerful independent prognostic factor of outcome, with high risk of early relapse and dismal outcome in patients achieving only PR or less. In this study, the heterogeneity was not only related to response; the authors found that patients, who had b2-microglobulin of $<4 \mathrm{mg} / \mathrm{L}$ and $\mathrm{Hb}$ level of $\geq 10 \mathrm{~g} / \mathrm{dL}$ at diagnosis (45\%), experienced improved survival after tandem transplant and benefited from HDT [18]. A clear separation of two groups of $\mathrm{t}(4 ; 14)$ patients was reported by the Arkansas group using a 70-gene expression model [19]. The results of the 260 myeloma patients, enrolled in the GEM-2000 Spanish transplant protocol, reinforced the previous results from other series and confirmed that the presence of $t(4 ; 14)$ was sufficient for shortening MM patient survival [20]. The poor prognosis of patients with $t(4 ; 14)$ may be in part due to its association with upregulation of the fibroblast growth factor receptor 3 (FGFR3). Data from the preclinical studies suggest that patients with increased expression of FGFR3 may benefit from the use of FGFR3 inhibitors [21]. Another interesting study showed that $t(4 ; 14)$ can be gained at time of relapse, which was observed in 14 out of 268 patients who did not express $\mathrm{t}(4 ; 14)$ at diagnosis. Hypotheses that explain the acquisition of the $t(4 ; 14)$ at relapse include evolution of already present subclones or its acquisition during evolution [22].

2.3.2. $t(11 ; 14)$. A different translocation involving immunoglobulin heavy chain gene on chromosome 14, which is commonly associated with lymphomas, especially mantle cell lymphoma, was identified in 24 cases of multiple myeloma, by standard cytogenetic analysis; in most of these cases $\mathrm{t}(11 ; 14)(\mathrm{q} 13 ; \mathrm{q} 32)$ was part of a complex karyotype and strong cyclin D1 overexpression by immunohistochemical stain [23]. In a large cohort including more than 350 myeloma patients, who participated in the Eastern Cooperative Oncology Group phase III clinical trial E9486, t(11;14)(q13;q32) was detected in approximately one-sixth of patients, and it was associated with a low serum monoclonal protein and plasma cell labeling index and is less likely to be hyperdiploid by DNA content analysis, which appeared to correlate with a better survival and prognosis in those patients [24]. The previous study, in addition to other studies, reported that the presence of $t(11 ; 14)(q 13 ; q 32)$ was always associated with small mature lymphoplasmacytoid morphology [24-26], and in more than $60 \%$ of the cases with CD20 expression [27]. Moreau et al. reported markedly improved long term survival in 26 patients with $\mathrm{t}(11 ; 14)(\mathrm{q} 13 ; \mathrm{q} 32)$ after HDT [28], whereas patients with this translocation, who were treated within the Eastern Cooperative Oncology Group protocol with HDT, showed borderline improvement [24]. However, no effect on survival or time to progression was seen in patients with $\mathrm{t}(11 ; 14)(\mathrm{q} 13 ; \mathrm{q} 32)$, treated with HDT at Mayo Clinic between 1990 and 2001 [16]. On the other hand, patients with $\mathrm{t}(11 ; 14)(\mathrm{q} 13 ; \mathrm{q} 32)$ showed higher risk of extramedullary plasmacytoma- (EMP-) specific relapse compared to other cytogenetic abnormalities $[29,30]$ and a lower response rate, if they have EMP at presentation [31], which is supposed to be due to downregulation of CD56, which facilitate disease dissemination and malignant plasma cells extramedullary spread [32, 33]. In a further analysis of three hundred and four patients with newly diagnosed MM treated at Mayo Clinic between January 2004 and December 2012, who underwent serial cytogenetic evaluations, patients with $t(11 ; 14)$ showed an increased cytogenetic stability during the follow-up, with decreased odds of cytogenetic evolution (odds ratio $(\mathrm{OR})=$ $0.22,95 \%$ confidence interval $(\mathrm{CI})=0.09-0.56, P=0.001)$ [34]. In contrast, Kaufman and colleagues reported inferior overall survival of patients with $t(11 ; 14)$ when compared with the classical standard risk patients in their cohort, which included 409 patients treated with HDT following doublet or triplet novel agent induction [35].

2.3.3. $t(14 ; 16)$. The data about $t(14 ; 16)$ are conflicting; on a retrospective analysis of over 1000 myeloma patients, the 32 patients with $\mathrm{t}(14 ; 16)$ did not show any survival difference from patients lacking this translocation, and it was not proved to be an independent prognostic factor on multivariate analysis [50], while some studies reported that $t(14 ; 16)$ have a negative impact on prognosis $[51,52]$.

2.3.4. Chromosome 13 Deletions. Chromosome 13 deletions either partial or complete detected by metaphase cytogenetics (CG) proved to have poor prognostic impact on patients with MM [53]. In subsequent studies, the rate of del(13q) detection was increased 2 to 3 times using interphase fluorescence in situ hybridization (FISH), but it remains an independent adverse prognostic [54-57]. In a further study that included 238 patients treated with HDT patients who expressed $13 \mathrm{q}$ del alone by FISH did not have a significantly shorter overall 
survival, but the presence of both $13 q$ del and $t(4 ; 14)$ together had a significant adverse effect on outcome [58]. In addition, the presence or absence of del(13q14) did not seem to affect overall response to single agent bortezomib in 62 patients with relapsed/refractory MM [59].

\subsubsection{7 p13 Deletion. TP53 gene is located at 17p13; deletion} of $17 \mathrm{p} 13$ is expressed in up to $11 \%$ of newly diagnosed myeloma patients. TP53 mutation, a well-known poor prognostic factor in many cancers, has also a strong correlation with poor outcome and resistance to therapy in patients with $\mathrm{MM}$, less frequently expressed at diagnosis, but it becomes more detected at relapse or with advanced disease [6062]. The work done by Lodè and colleagues showed that TP53 mutations are exclusively associated with del(17p); by sequencing for TP53 gene in 92 newly diagnosed myeloma patients, $37 \%$ of 54 patients with del(17p) have mutations of the TP53 gene (63\% are homozygous), while none of the patients without del(17p) expressed TP53 mutation [60]. It is evident that the negative prognostic impact of $\operatorname{del}(17 \mathrm{p})$ is demonstrated when at least $60 \%$ of plasma cells have it [63].

2.3.6. Chromosome 1 Abnormalities. Chromosome 1 abnormalities are frequently detected in MM [31]; del 1p lead to loss of tumor suppressor genes and emerged as a poor prognostic factor in myeloma $[64,65]$. The adverse prognostic role was confirmed in a study, which included 15 patients with del 1p; associated $13 \mathrm{q}$ del was detected in 10 out of the 15 patients. Del 1p did not affect PFS in these patients after HDT and Autotransplant [66]. In addition, the role of chromosome 1 abnormalities was investigated in elderly patients ( $>65$ years) enrolled in a phase III randomized clinical trial comparing VMP versus VMPT-VT; the abnormalities are when thalidomide appears to have a detrimental effect in elderly patients with newly diagnosed MM and abnormal chrl, while bortezomib can overcome its negative prognostic impact [67].

2.3.7. Gene Expression Profile (GEP). Several studies tried to identify molecular subgroups of multiple myeloma, using gene expression profiling on purified by CD138+ plasma cells. A study done in the University of Arkansas for Medical Science (UAMS), using plasma cells (PCs) from 74 newly diagnosed myeloma patients, 5 with monoclonal gammopathy of undetermined significance (MGUS), and 31 healthy volunteers (normal PCs), identified 4 distinct subgroups of MM (MM1, MM2, MM3, and MM4), ranging from MM1 that is more like normal PCs and MGUS, whereas MM4 showed more poor prognostic features as abnormal karyotype and high serum b2-microglobulin levels [68]. In a later study from (UAMS), they defined 7 subgroups rather than 4, using samples from over 400 newly diagnosed myeloma patients and more specific genes such as c-MAF and MAFB, CCND1, CCND3, ASS, IL6R, MMSET, FGFR3, CCNB2, FRZB, and DKK1. They described the UAMS classification 7 clusters, CD-1, CD-2, MS, MF, HY, PR, and LB [69]. Three novel subsets of multiple myeloma were identified, using data of the 320 newly diagnosed myeloma patients included in the Dutch-Belgian/German HOVON-65/GMMG-HD4 trial, in addition to 7 subgroups described in the 2006 UAMS classification, which were $\mathrm{NF} \kappa \mathrm{B}, \mathrm{CTA}$, and PRL3 clusters [70].

Myeloma can be roughly divided into two equal disease entities: hyperdiploid multiple myeloma (H-MM) and Nonhyperdiploid multiple myeloma (NH-MM). A gene expression profiling study was conducted at Mayo Clinic trying to characterize the molecular profile of H-MM. Four nonoverlapping clusters were identified, each with distinct clinical and biological features, including a subgroup with a poor prognosis and a subgroup that responds fairly well to bortezomib [71].

The 15 most stable genes associated with survival from the 7,508-gene set used in the IFM 99 trials were used to stratify myeloma patients included in the trials into low-risk and high-risk groups; the authors concluded that high-risk patients have a 6.8-fold increased risk of death compared with low-risk patients (95\% CI, 3.92 to $11.73 ; P<0.001$ ), with more than $90 \%$ survival rates for low-risk group and less than $50 \%$ for high-risk group at 3 years [72].

Another gene signature called EMC-92-gene signature was generated from gene expression profile used in the HOVON65/GMMG-HD4 trial. The performance of the EMC-92-gene signature was validated in newly diagnosed and relapsed myeloma patients, and it was proved to be independent of other prognostic factors on multivariate analysis. In addition, it was reported to be the best compared to other used signatures [73]. In another study done by Kuiper et al., they evaluated twenty risk markers, including $\mathrm{t}(4 ; 14)$ and deletion of 17p (FISH), EMC92, and UAMS70 (GEP classifiers), and ISS. Their results showed that the EMC92-ISS combination is the strongest predictor for overall survival, resulting in a 4-group risk classification. The median survival was 24 months for the highest risk group and 47 and 61 months for the intermediate risk groups, and the median was not reached after 96 months for the lowest risk group [74].

2.4. Risk Stratification Models. Several risk stratification models have been developed for prognostication of MM patients. The most widely used are shown in Table 1.

\section{Monitoring of Response Tools}

3.1. Serum Light Chain Assay. Standard work-up of newly diagnosed MM includes assessment of both serum and urine for monoclonal protein. These biological markers have also proven to be essential in the disease progression detection and monitoring. A panel of members of the 2009 International Myeloma Workshop developed guidelines for standard investigative work-up of patients with suspected multiple myeloma. Both serum and urine should be assessed for monoclonal protein. Measurement of monoclonal protein both by the densitometer tracing and/by nephelometric quantitation is recommended, and immunofixation is required for confirmation. The serum-free light chain (sFLC) assay is recommended in all newly diagnosed patients with plasma cell dyscrasias [75]. Multiple studies have showed sFLCR to be a superior prognostic marker for plasma cell dyscrasias in contrast to M-spike. As an example, Dimopoulos et al. 
TABLE 1: Various risk stratification models.

\begin{tabular}{llll}
\hline Risk stratification model & Prognostic markers & OS & Reference \\
\hline \multirow{3}{*}{ mSMART } & (i) Cytogenetics & (i) Low risk: 10 years & [36] \\
& (ii) GEP & (ii) Intermediate risk: 4.5 years \\
& (iii) PCLI & (iii) High risk: 3 years & [37] \\
IMWG & (i) ISS & (i) Low risk: >10 years \\
& (ii) Cytogenetics & (ii) Standard risk: 7 years \\
\hline \multirow{2}{*}{ IFM } & (iii) High risk: 2 years & LDH & Score 0-3. Score 3 had very poor prognosis \\
& (ii) ISS & & \\
\hline
\end{tabular}

showed that, in patients with monoclonal gammopathy of undetermined significance (MGUS), the risk of progression in patients with an abnormal sFLC ratio (sFLCR) was significantly higher compared with patients with a normal ratio (hazard ratio, 3.5; 95\% confidence interval [CI], 2.3-5.5; $P<$ 0.001 ) and was independent of the size and type of the serum monoclonal (M) protein [75]. For patients with smoldering MM (SMM), Rajkumar et al. demonstrated that a high sFLCR $>100$ is a predictor of imminent progression, and such patients may be considered candidates for early treatment intervention [76]. The prognostic value of sFLC was also seen in patients with solitary plasmacytoma of bone with significant higher progression to $\mathrm{MM}$ in patients with abnormal sFLCR [77]. In MM, abnormal sFLCR was shown to be an independent prognostic factor, with one study showing 5year disease-specific survival of $82 \%$ in patients with sFLCR $\leq$ than the median compared to $30 \%$ in patients with sFLCR > the median $(P=0.0001)$ [78]. Because the half-life of FLC is $<6$ hours, FLC measurements at short sampling intervals allow real-time measurement of treatment-induced tumor kill and provide prompt indications of chemosensitivity [79].

\subsection{Serum Heavy/Light Chain (HLC) Assay (Hevylite).} Immunofixation (IFE) is a standard method for detecting monoclonal immunoglobulins and characterizing its isotype. Recently clonality can also be determined by using immunoglobulin (Ig) heavy chain/light chain immunoassays (HLC), Hevylite. HLC separately measures in pairs light chain types of each intact Ig class generating ratio of monoclonal Ig/uninvolved polyclonal Ig concentrations [80]. Studies have shown that the HLC ratio (HLCR) is of prognostic significance in MM. According to results from a study by Koulieris et al. [81], high HLCR was associated with anemia, high serum FLCR, extensive bone marrow infiltration, and increased $\beta 2$-microglobulin. In addition, increased HLCR and the presence of immunoparesis correlated with time to treatment initiation. Patients with high HLCR had a significantly shorter survival $(P=0.022)$. At the moment, HLC is considered novel immunoassays with multiple studies showing its utility in disease monitoring and outcome prediction in plasma cell dyscrasias. Its use is currently being cleared by the US Food and Drug Agency (FDA).
3.2.1. Advanced Imaging Modalities. Imaging studies in MM include metastatic skeletal survey (MSS), computed tomography $(\mathrm{CT})$, magnetic resonant imaging (MRI), and, more recently, positron emission tomography (PET) with fluorodeoxyglucose (FDG). MSS continues to be the standard diagnostic study in MM. Unfortunately, for MSS to detect bone destruction, the damage has to reach approximately $50 \%$ [82]. The national cancer center network (NCCN) MM panel recommends additional tests that may be useful under some circumstances. These include MRI and PET/CT [83]. Both MRI and PET scan are proven to give important information in patients with MM including detection of bone lesions, bone marrow infiltration, and disease monitoring posttherapy. A study by Baur-Melnyk et al. showed that patients without bone marrow infiltration have a significantly longer survival than patients with bone marrow infiltration in MRI at the time of diagnosis. However, even in stage I disease (Durie and Salmon) and negative X-ray films bone marrow infiltration in MRI may be detected in $29-50 \%$ of patients. Those patients typically show an earlier disease progression [84]. IMWG consensus considered MRI to be the goldstandard imaging technique for detection of bone morrow involvement [85]. The panel also discussed the prognostic value of MRI explaining that focal pattern on MRI gives prognostic information in symptomatic MM, and diffuse pattern also correlates with worse prognosis. Another study by Bredella et al. evaluated the value of FDG PET in the assessment of patient with MM and showed that FDG PET has sensitivity in detecting myelomatous involvement of $85 \%$ and specificity of $92 \%$. FDG PET is able to detect bone marrow involvement in patients with MM and it is useful in assessing extent of disease at time of initial diagnosis, contributing to staging that is more accurate [86].

Despite numerous potential advantages of both MRI and PET-CT in MM, they are not yet the established gold standard for disease evaluation at diagnosis or at completion of therapy. Concerns with the serial use of these techniques exist due to the heterogeneity of visual criteria and the lack of consistency in the interpretation of results. Standardization of disease definitions for MRI and PET-CT imaging is needed to improve the specificity and positive predictive value of these tools [87]. 
Novel techniques can detect more lytic lesions compared to conventional radiography. Whole body, multidetector, low-dose computed tomography (WBLD-CT) is more sensitive for the detection of lytic lesions in myeloma compared to conventional radiography; it is very easy to perform (the examination is performed in 2 min or less), has a more accurate evaluation of areas with instability or at risk of fracture, and is superior regarding the planning for radiotherapy or surgical interventions [88].

For initial diagnosis of patients with multiple myeloma bone disease, use of an imaging test with a superior detection rate such as WBLDCT would find more lesions and presumably upstage patients, but definitive studies have yet to be completed defining the prognostic value of WBLDCT. WBLDCT can reliably exclude bone disease to confirm MGUS and complement laboratory monitoring. It remains unproven whether clinical benefit could be obtained by treating patients earlier or more aggressively based on WBLDCT findings. Nevertheless, recent data showing that early treatment of smoldering multiple myeloma leads to improved overall survival suggest that a more sensitive imaging method might help to detect lytic lesions and provide earlier treatment and thus improve survival [89]. Currently WBLDCT is considered a diagnostic tool, not a prognostic one.

\section{Minimal Residual Disease (MRD) Monitoring Methods}

4.1. Circulating Plasma Cells. Circulating PC detected by flow cytometry also is considered one of predictors of survival in patients with newly diagnosed MM. Nowakowski et al. studied the relationship between the number of circulating PCs in patients with newly diagnosed MM and survival and they concluded that it is an independent predictor of survival [90]. The increase in PC may be accompanied by morphological differences, like plasmablastic features, and can distinguish patients with a poor prognosis. Greipp et al. studied the prognostic significance of plasmablastic (PB) $\mathrm{MM}$ and the authors concluded that $\mathrm{PB} \mathrm{MM}$ is a discrete entity associated with more aggressive disease and shortened survival [91]. However, since the prognostic values of these factors are not easily reproducible, they are not widely adopted [92].

4.2. Minimal Residual Disease (MRD). It is currently well established that there is a direct relationship between depth of response and prolonged survival in MM [93, 94]. Still, the vast majority of patients who achieve complete response (CR) per the current definition criteria will eventually relapse. Because of that, the international Myeloma Working Group (IMWG), working on refining the criteria of CR in an effort to improve the outcome of the patients and in 2006, introduced normalization of sFLCs and absence of clonal PCs in BM biopsies by immunohistochemistry and/or immunofluorescence as additional requirements to define more stringent CR criteria [95]. Another CR definition that had emerged is molecular complete response (mCR), which is defined as absence of detectable disease by polymerase chain reaction
(PCR) for Ig gene rearrangement [96]. Currently, the most sensitive approaches to detect MRD in MM include Multiparameter Flow Cytometry (MFC) and Ig allele-specific oligonucleotide-based quantitative PCR (ASO-PCR) [29]. The role of next generation sequencing (NGS) of Ig genes is emerging as a future sensitive tool to assess MRD. The sensitivity of these methods is comparable (MFC: $10^{-5}$ to $10^{-6}$, ASO-PCR: $10^{-5}$ to $10^{-6}$, NGS: $10^{-6}$ ) [97].

The prognostic value of MRD in MM has been explored in multiple studies. San Miguel et al. [98] studied the prognostic value of multiparametric immunophenotyping of PC compartment in patients with MM and found that ASCT provided a significantly greater reduction in the level of residual tumor PCs and with better recovery of normal PCs. The authors also found that patients in whom at least $30 \%$ of gated PCs had a normal phenotype after treatment had a significantly longer progression-free survival (60 months versus 34 months; $P=0.02$ ). Paiva et al. on behalf of the GEM/PETHEMA cooperative study group [99] showed in MM patients who were treated with ASCT that median PFS (71 versus 37 months, $P<0.001$ ) and median OS (not reached versus 89 months, $P<.002$ ) were longer in patients who were MRD negative versus MRD positive by multiparameter flow at day 100 after ASCT. Puig et al. compared ASO RQ-PCR with multiparameter FCM in patients with MM and found a significant correlation in MRD quantitation by both techniques $(r=0.881, P<0.001)$, being reflective of treatment intensity. Patients with $<10^{-4}$ residual tumor cells showed PFS compared with the rest (not reached (NR) versus 31 months, $P=0.002)$, with similar results observed with MFC. Among complete responders $(n=62)$, PCR discriminated two risk groups with different PFS (49 versus 26 months, $P=0.001$ ) and overall survival (NR versus 60 months, $P=$ 0.008) [100]. Martinez-Lopez et al. assessed the prognostic value of MRD detection in MM patients using a NGS tool and showed that the applicability of deep sequencing was 91\%. Concordance between sequencing and MFC and ASOPCR was $83 \%$ and $85 \%$, respectively. Patients who were MRD- by sequencing had a significantly longer time to tumor progression (TTP) (median 80 versus 31 months; $P<0.0001$ ) and overall survival (median not reached versus 81 months; $P=0.02$ ), compared with patients who were MRD+ [101]. The conclusion from the above-mentioned studies and many other studies is that MRD assessment in MM using different methods is associated with improvement in PFS and OS which supports the rationale for implementing MRD assessment to redefine and improve current CR criteria in MM [97].

Another way of detecting MRD is by the use of MRI and PET/CT through the detection of possible patchy BM infiltration or extramedullary involvement with an MRDnegative BM [97]. MRI is very sensitive in detecting bone marrow involvement in the spine. PET/CT is able to detect extramedullary disease which has an adverse prognostic impact [102].

A study that compared PET/CT and whole body MRI in transplant-candidate patients showed that, against conventional response criteria, PET/CT had the same sensitivity but higher specificity than whole body MRI [103]. 
TABLE 2: Summary of some of the novel prognostic markers that were published recently.

\begin{tabular}{|c|c|c|}
\hline Authors & Novel prognostic marker & Conclusion \\
\hline Li et al. 2015 [39] & $\begin{array}{l}\text { The expression patterns of } \\
\text { miR-15a/16-1 }\end{array}$ & $\begin{array}{l}\text { miR-15a seems to be linked with disease progression } \\
\text { and prognosis while miR-16-1 acts as a valuable } \\
\text { diagnostic marker }\end{array}$ \\
\hline Wang et al. 2015 [40] & Immune checkpoint signaling & $\begin{array}{l}\text { The overall response rate to treatment was higher in low } \\
\text { sPD-L1 patients than in high sPD-L1 patients }\end{array}$ \\
\hline Jung et al. 2016 [41] & $\begin{array}{l}\text { Inverse platelet to lymphocyte ratio } \\
\text { (iPLR) }\end{array}$ & $\begin{array}{l}\text { Staging by iPLR group had predictive value for PFS and } \\
\text { OS }\end{array}$ \\
\hline Zhou et al. 2015 [42] & $\begin{array}{l}\text { Dysregulated long noncoding RNAs } \\
\text { (lncRNAs) }\end{array}$ & $\begin{array}{l}\text { Four lncRNAs were identified to be significantly } \\
\text { associated with OS }\end{array}$ \\
\hline Lee et al. 2015 [43] & $\begin{array}{l}\text { Bone marrow (BM) microvessel } \\
\text { density (MVD) }\end{array}$ & $\begin{array}{l}\text { PFS was significantly lower in the high MVD group } \\
\text { than in the low MVD group }\end{array}$ \\
\hline Ma et al. 2015 [44] & $\mathrm{N}$-Cadherin & $\begin{array}{l}\text { OS is worse with high expression of N-Cadherin which } \\
\text { may be related to 1q21 amplification. }\end{array}$ \\
\hline Lullo et al. 2015 [45] & Th22 cells & $\begin{array}{l}\text { Increased frequency of IL-22(+)IL-17(-)IL-13(+) T cells } \\
\text { correlates with poor prognosis }\end{array}$ \\
\hline Li et al. 2015 [46] & Downregulated miR-33b & $\begin{array}{l}\text { miR-33b low expression had significantly shortened } \\
\text { PFS and OS }\end{array}$ \\
\hline Bolomsky et al. 2015 [47] & $\begin{array}{l}\text { Insulin-like growth factor binding } \\
\text { protein } 7 \text { (IGFBP7) expression }\end{array}$ & $\begin{array}{l}\text { IGFBP7 expression is linked to translocation } \mathrm{t}(4 ; 14) \\
\text { showing clinical features of adverse prognosis }\end{array}$ \\
\hline Jung et al. 2015 [48] & Autophagic markers beclin 1 and LC3 & $\begin{array}{l}\text { Higher immunoreactivity for autophagic markers in } \\
\text { MM is associated with superior patient survival }\end{array}$ \\
\hline Trotter et al. 2015 [49] & Myeloma cell-derived Runx2 & $\begin{array}{l}\text { Runx2 expression is a major regulator of } \mathrm{MM} \\
\text { progression in bone and myeloma bone disease }\end{array}$ \\
\hline
\end{tabular}

Many studies have shown the value of MRD diagnostics for evaluation of the efficacy of specific treatment stages. Both the Spanish [104] and UK [105] study groups showed the importance of MRD in identifying chemosensitivity before and after ASCT. Failure to eradicate MRD levels before ASCT will show significantly superior PFS if MRD negativity is achieved after ASCT. Another example is a study by Rawstron et al. that showed that patients who achieved MRD negativity with maintenance therapy experienced significantly prolonged PFS [105].

Depth of response was evaluated in different studies. An early study of 126 consecutive patients, of whom $33 \%$ achieved CR with SCT, CR did not influence outcome, on either high or low-risk group [99]. Another study at Mayo Clinic showed no significant difference in time to progression (TTP) between the small group of patients who achieved CR before HDTASCT (BCR) and those who achieved CR after HDT-ASCT (ACR), at more than 6 years follow-up, and the median OS was not reached at time of analysis [100]. With the advent of novel agents, more $\mathrm{CR}$ rates are achieved and its prognostic impact is studied in both relapsed and newly diagnosed MM. Multiple prospective studies of newly diagnosed myeloma patients demonstrated either a longer EFS and/or a better OS in patients who achieved CR or at least VGPR, after a single [101, 102] or tandem ASCT [103-106]. In a large series, including 1000 patients treated with MEL-based tandem high-dose therapy (HDT) trials with autologous hematopoietic stem cell (AHSC) support, superior overall survival was seen in relapsed patients, who achieved a complete remission [107]. However, in a retrospective study which analyzed the outcome of over 500 patients who did not achieve at least a PR after initial induction, there was no difference in median OS between patients who received salvage chemotherapy and those who did not receive any additional therapy to augment response prior to transplant [108]. At this time, we believe that new tools of disease burden are needed to define CR in a more precise way in the era of newer treatments and to study the impact of deeper CR on overall survival.

\section{Novel Prognostic Markers in MM}

Over the past year, there were multiple publications on novel prognostic markers in MM. These include markers in immunophenotyping, genetics, immune signaling, biomarkers, bone marrow environment, and imaging techniques. We selected some of these novel markers. Table 2 provides summary of some of these promising markers.

\section{Conclusion and Future Directions}

Understanding the prognostic factors in MM is important for optimal care of MM patients.

Our comprehension of the prognostic markers in MM has developed significantly over the last 10 years. Incorporation of different prognostic markers of MM in risk stratification of the disease is evolving with the presence of multiple models in the literature. The ultimate goal of establishing prognostic models in $\mathrm{MM}$ is to develop risk-adaptive therapeutic strategies. Our aim of this review is to summarize the current standard prognostic markers used in MM along with novel techniques that are still in development and highlight 
their implications in current clinical practice. Currently, the most powerful prognostic markers in MM that has clinical implication are genetics abnormalities. The classification of MM into high risk, intermediate risk, and standard risk is based primarily on the impact of genetic aberrations. Selection of therapies nowadays is also directed by this risk stratification. Development of novel prognostic markers is evolving and soon will be part of the standard risk classification in MM and these include GEP and next generation sequencing (NGS).

We believe that refinement of the prognostic models in MM will eventually lead to enhancement of the efficacy of the therapeutic approaches and ultimately will improve the outcome of the disease.

\section{Competing Interests}

All authors do not have financial disclosure.

\section{References}

[1] P. P. Carbone, L. E. Kellerhouse, and E. A. Gehan, "Plasmacytic myeloma. A study of the relationship of survival to various clinical manifestations and anomalous protein type in 112 patients," The American Journal of Medicine, vol. 42, no. 6, pp. 937-948, 1967.

[2] G. Costa, R. L. Engle, A. Schilling et al., "Melphalan and prednisone: an effective combination for the treatment of multiple myeloma," The American Journal of Medicine, vol. 54, no. 5, pp. 589-599, 1973.

[3] B. G. M. Durie and S. E. Salmon, "A clinical staging system for multiple myeloma," Cancer, vol. 36, pp. 842-854, 1975.

[4] P. R. Greipp, J. S. Miguel, B. G. M. Dune et al., "International staging system for multiple myeloma," Journal of Clinical Oncology, vol. 23, no. 15, pp. 3412-3420, 2005.

[5] G. Merlini, J. G. Waldenstrom, and S. D. Jayakar, "A new improved clinical staging system for multiple myeloma based on analysis of 123 treated patients," Blood, vol. 55, no. 6, pp. 10111019, 1980.

[6] R. Bataille, B. G. M. Durie, J. Grenier, and J. Sany, "Prognostic factors and staging in multiple myeloma: a reappraisal," Journal of Clinical Oncology, vol. 4, no. 1, pp. 80-87, 1986.

[7] J. Blade, C. Rozman, F. Cervantes, J.-C. Reverter, and E. Montserrat, "A new prognostic system for multiple myeloma based on easily available parameters," British Journal of Haematology, vol. 72, no. 4, pp. 507-511, 1989.

[8] Medical Research Council's Working Party on Leukemia in Adults, "Prognostic features in the third MRC myelomatosis trial," British Journal of Cancer, vol. 42, no. 6, pp. 831-840, 1980.

[9] P. N. Hari, M.-J. Zhang, V. Roy et al., "Is the international staging system superior to the Durie-Salmon staging system? A comparison in multiple myeloma patients undergoing autologous transplant," Leukemia, vol. 23, no. 8, pp. 1528-1534, 2009.

[10] A. Palumbo, H. Avet-Loiseau, S. Oliva et al., "Revised international staging system for multiple myeloma: a report from international myeloma working group," Journal of Clinical Oncology, vol. 33, no. 26, pp. 2863-2869, 2015.

[11] S. Kumar, S. V. Rajkumar, P. R. Greipp, and T. E. Witzig, "Cell proliferation of myeloma plasma cells: comparison of the blood and marrow compartments," American Journal of Hematology, vol. 77, no. 1, pp. 7-11, 2004.
[12] P. R. Greipp, J. A. Lust, W. M. O’Fallon, J. A. Katzmann, T. E. Witzig, and R. A. Kyle, "Plasma cell labeling index and $\beta 2$-microglobulin predict survival independent of thymidine kinase and C-reactive protein in multiple myeloma," Blood, vol. 81, no. 12, pp. 3382-3387, 1993.

[13] D. P. Steensma, M. A. Gertz, P. R. Greipp et al., "A high bone marrow plasma cell labeling index in stable plateau-phase multiple myeloma is a marker for early disease progression and death," Blood, vol. 97, no. 8, pp. 2522-2523, 2001.

[14] C. Li, L. Chen, X. Gao et al., "Plasma cell labeling index correlates with deletion of 13q14 in multiple myeloma," Leukemia and Lymphoma, vol. 52, no. 2, pp. 260-264, 2011.

[15] J. J. Keats, T. Reiman, C. A. Maxwell et al., "In multiple myeloma, $\mathrm{t}(4 ; 14)(\mathrm{p} 16 ; \mathrm{q} 32)$ is an adverse prognostic factor irrespective of FGFR3 expression,” Blood, vol. 101, no. 4, pp. 1520-1529, 2003.

[16] M. A. Gertz, M. Q. Lacy, A. Dispenzieri et al., "Clinical implications of $\mathrm{t}(11 ; 14)(\mathrm{q} 13 ; \mathrm{q} 32), \mathrm{t}(4 ; 14)(\mathrm{p} 16.3 ; \mathrm{q} 32)$, and $-17 \mathrm{p} 13$ in myeloma patients treated with high-dose therapy," Blood, vol. 106, no. 8, pp. 2837-2840, 2005.

[17] W. Jaksic, S. Trudel, H. Chang et al., "Clinical outcomes in $\mathrm{t}(4 ; 14)$ multiple myeloma: a chemotherapy-sensitive disease characterized by rapid relapse and alkylating agent resistance," Journal of Clinical Oncology, vol. 23, no. 28, pp. 7069-7073, 2005.

[18] P. Moreau, M. Attal, F. Garban et al., "Heterogeneity of t(4;14) in multiple myeloma. Long-term follow-up of 100 cases treated with tandem transplantation in IFM99 trials," Leukemia, vol. 21, no. 9, pp. 2020-2024, 2007.

[19] J. D. Shaughnessy Jr., F. Zhan, B. E. Burington et al., "Avalidated gene expression model of high-risk multiple myeloma is defined by deregulated expression of genes mapping to chromosome 1," Blood, vol. 109, no. 6, pp. 2276-2284, 2007.

[20] N. C. Gutiérrez, M. V. Castellanos, M. L. Martín et al., "Prognostic and biological implications of genetic abnormalities in multiple myeloma undergoing autologous stem cell transplantation: $\mathrm{t}(4 ; 14)$ is the most relevant adverse prognostic factor, whereas $\mathrm{RB}$ deletion as a unique abnormality is not associated with adverse prognosis," Leukemia, vol. 21, no. 1, pp. 143-150, 2007.

[21] A. Kalff and A. Spencer, "The t(4;14) translocation and FGFR3 overexpression in multiple myeloma: prognostic implications and current clinical strategies," Blood Cancer Journal, vol. 2, article no. 37, 2012.

[22] B. Hébraud, D. Caillot, J. Corre et al., "The translocation t(4;14) can be present only in minor subclones in multiple myeloma," Clinical Cancer Research, vol. 19, no. 17, 2013.

[23] J. D. Hoyer, C. A. Hanson, R. Fonseca, P. R. Greipp, G. W. Dewald, and P. J. Kurtin, “The $(11 ; 14)(\mathrm{q} 13 ; \mathrm{q} 32)$ translocation in multiple myeloma: A Morphologic and Immunohistochemical Study," American Journal of Clinical Pathology, vol. 113, no. 6, pp. 831-837, 2000.

[24] R. Fonseca, E. A. Blood, M. M. Oken et al., "Myeloma and the $\mathrm{t}(11 ; 14)(\mathrm{q} 13 ; \mathrm{q} 32)$; evidence for a biologically defined unique subset of patients," Blood, vol. 99, no. 10, pp. 3735-3741, 2002.

[25] R. Garand, H. Avet-Loiseau, F. Accard, P. Moreau, J. L. Harousseau, and R. Bataille, "t(11;14) and $t(4 ; 14)$ translocations correlated with mature lymphoplasmacytoid and immature morphology, respectively, in multiple myeloma," Leukemia, vol. 17, no. 10, pp. 2032-2035, 2003.

[26] H. Avet-Loiseau, R. Garand, L. Lodé, J.-L. Harousseau, and R. Bataille, "Translocation $\mathrm{t}(11 ; 14)(\mathrm{q13} ; \mathrm{q} 32)$ is the hallmark of IgM, IgE, and nonsecretory multiple myeloma variants," Blood, vol. 101, no. 4, pp. 1570-1571, 2003. 
[27] N. Robillard, H. Avet-Loiseau, R. Garand et al., "CD20 is associated with a small mature plasma cell morphology and $\mathrm{t}(11 ; 14)$ in multiple myeloma," Blood, vol. 102, no. 3, pp. 1070-1071, 2003.

[28] P. Moreau, T. Facon, X. Leleu et al., "Recurrent 14q32 translocations determine the prognosis of multiple myeloma, especially in patients receiving intensive chemotherapy," Blood, vol. 100, no. 5, pp. 1579-1583, 2002.

[29] R. Fonseca, T. E. Witzig, M. A. Gertz et al., "Multiple myeloma and the translocation $\mathrm{t}(11 ; 14)(\mathrm{q} 13 ; \mathrm{q} 32)$ : a report on 13 cases," British Journal of Haematology, vol. 101, no. 2, pp. 296-301, 1998.

[30] E. Parkins, M. Boll, S. J. M. O’Connor, A. C. Rawstron, and R. G. Owen, "Extramedullary plasmacytoma with a t(11;14)(q13;q32) and aggressive clinical course," Leukemia and Lymphoma, vol. 51, no. 7, pp. 1360-1362, 2010.

[31] J. D. Shaughnessy, F. Zhan, B. E. Burington et al., "A validated gene expression model of high-risk multiple myeloma is defined by deregulated expression of genes mapping to chromosome 1 ," Blood, vol. 109, no. 6, pp. 2276-2284, 2007.

[32] H.-J. Shin, K. Kim, J.-J. Lee et al., “The t(11;14)(q13;q32) translocation as a poor prognostic parameter for autologous stem cell transplantation in myeloma patients with extramedullary plasmacytoma," Clinical Lymphoma, Myeloma and Leukemia, vol. 15, no. 4, pp. 227-235, 2015.

[33] G. An, Y. Xu, L. Shi et al., “T(11;14) multiple myeloma: a subtype associated with distinct immunological features, immunophenotypic characteristics but divergent outcome," Leukemia Research, vol. 37, no. 10, pp. 1251-1257, 2013.

[34] M. Binder, S. V. Rajkumar, R. P. Ketterling et al., "Occurrence and prognostic significance of cytogenetic evolution in patients with multiple myeloma," Blood Cancer Journal, vol. 6, 2016.

[35] G. P. Kaufman, M. A. Gertz, A. Dispenzieri et al., "Impact of cytogenetic classification on outcomes following early highdose therapy in multiple myeloma," Leukemia, vol. 30, no. 3, pp. 633-639, 2015.

[36] J. R. Mikhael, D. Dingli, V. Roy et al., "Management of newly diagnosed symptomatic multiple myeloma: updated mayo stratification of myeloma and risk-adapted therapy (mSMART) consensus guidelines 2013," Mayo Clinic Proceedings, vol. 88, no. 4, pp. 360-376, 2013.

[37] H. Iriuchishima, T. Saitoh, H. Handa et al., "A new staging system to predict prognosis of patients with multiple myeloma in an era of novel therapeutic agents," European Journal of Haematology, vol. 94, no. 2, pp. 145-151, 2015.

[38] P. Moreau, M. Cavo, P. Sonneveld et al., "Combination of International Scoring System 3, highlactate dehydrogenase, and $\mathrm{t}(4 ; 14)$ and/or del(17p) identifies patients with multiple myeloma (MM) treated with front-line autologous stem-cell transplantation at high risk of early MM progression-related death," Journal of Clinical Oncology, vol. 32, no. 20, pp. 2173-2180, 2014.

[39] F. Li, Y. Xu, S. Deng et al., "MicroRNA-15a/16-1 cluster located at chromosome 13q14 is down-regulated but displays different expression pattern and prognostic significance in multiple myeloma," Oncotarget, vol. 6, no. 35, pp. 38270-38282, 2015.

[40] L. Wang, H. Wang, H. Chen et al., "Serum levels of soluble programmed death ligand 1 predict treatment response and progression free survival in multiple myeloma," Oncotarget, vol. 6, no. 38, pp. 41228-41236, 2015.

[41] S.-H. Jung, J. S. Kim, W. S. Lee et al., "Prognostic value of the inverse platelet to lymphocyte ratio (iPLR) in patients with multiple myeloma who were treated up front with a novel agentcontaining regimen," Annals of Hematology, vol. 95, no. 1, pp. 55-61, 2016.
[42] M. Zhou, H. Zhao, Z. Wang et al., "Identification and validation of potential prognostic lncRNA biomarkers for predicting survival in patients with multiple myeloma," Journal of Experimental and Clinical Cancer Research, vol. 34, article 102, 2015.

[43] N. Lee, H. Lee, S. Y. Moon et al., "Adverse prognostic impact of bone marrow microvessel density in multiple myeloma," Annals of Laboratory Medicine, vol. 35, no. 6, pp. 563-569, 2015.

[44] J. Ma, Q.-F. Yu, X.-Y. Liu et al., "Expression of N-cadherin in patients with multiple myeloma and its clinical significance," Zhongguo Shi Yan Xue Ye Xue Za Zhi, vol. 23, no. 4, pp. 10441048, 2015.

[45] G. D. Lullo, M. Marcatti, S. Heltai et al., "Th22 cells increase in poor prognosis multiple myeloma and promote tumor cell growth and survival," OncoImmunology, vol. 4, no. 5, 2015.

[46] F. Li, M. Hao, X. Feng et al., "Downregulated miR-33b is a novel predictor associated with disease progression and poor prognosis in multiple myeloma," Leukemia Research, vol. 39, no. 7, pp. 793-799, 2015.

[47] A. Bolomsky, D. Hose, M. Schreder et al., "Insulin like growth factor binding protein 7 (IGFBP7) expression is linked to poor prognosis but may protect from bone disease in multiple myeloma," Journal of Hematology and Oncology, vol. 8, article 10, Article ID 13045, 2015.

[48] G. Jung, J. Roh, H. Lee et al., "Autophagic markers BECLIN 1 and LC3 are associated with prognosis of multiple myeloma," Acta Haematologica, vol. 134, no. 1, pp. 17-24, 2015.

[49] T. N. Trotter, M. Li, Q. Pan et al., "Myeloma cell-derived Runx2 promotes myeloma progression in bone," Blood, vol. 125, no. 23, pp. 3598-3608, 2015.

[50] I. Vande Broek, K. Vanderkerken, B. Van Camp, and I. Van Riet, "Extravasation and homing mechanisms in multiple myeloma," Clinical and Experimental Metastasis, vol. 25, no. 4, pp. 325-334, 2008.

[51] H. Avet-Loiseau, F. Malard, L. Campion et al., "Translocation $\mathrm{t}(14 ; 16)$ and multiple myeloma: is it really an independent prognostic factor?” Blood, vol. 117, no. 6, pp. 2009-2011, 2011.

[52] B. Nair, F. Van Rhee, J. D. Shaughnessy Jr. et al., "Superior results of total therapy 3 (2003-33) in gene expression profiling-defined low-risk multiple myeloma confirmed in subsequent trial 200666 with VRD maintenance," Blood, vol. 115, no. 21, pp. 41684173,2010 .

[53] R. Fonseca, "Clinical and biologic implications of recurrent genomic aberrations in myeloma," Blood, vol. 101, no. 11, pp. 4569-4575, 2003.

[54] G. Tricot, B. Barlogie, S. Jagannath et al., "Poor prognosis in multiple myeloma is associated only with partial or complete deletions of chromosome 13 or abnormalities involving 11q and not with other karyotype abnormalities," Blood, vol. 86, no. 11, pp. 4250-4256, 1995.

[55] N. Zojer, R. Königsberg, J. Ackermann et al., "Deletion of 13q14 remains an independent adverse prognostic variable in multiple myeloma despite its frequent detection by interphase fluorescence in situ hybridization," Blood, vol. 95, no. 6, pp. 1925-1930, 2000.

[56] N. Worel, H. Greinix, J. Ackermann et al., "Deletion of chromosome 13q14 detected by FISH has prognostic impact on survival after high-dose therapy in patients with multiple myeloma," Annals of Hematology, vol. 80, pp. 345-348, 2001.

[57] R. Fonseca, D. Harrington, M. M. Oken et al., "Biological and prognostic significance of interphase fluorescence in situ hybridization detection of chromosome 13 abnormalities $(\Delta 13)$ in 
multiple myeloma: An Eastern Cooperative Oncology Group Study," Cancer Research, vol. 62, no. 3, pp. 715-720, 2002.

[58] H. Kaufmann, E. Krömer, T. Nösslinger et al., "Both chromosome 13 abnormalities by metaphase cytogenetics and deletion of $13 q$ by interphase FISH only are prognostically relevant in multiple myeloma," European Journal of Haematology, vol. 71, no. 3, pp. 179-183, 2003.

[59] V. Sagaster, H. Ludwig, H. Kaufmann et al., "Bortezomib in relapsed multiple myeloma: response rates and duration of response are independent of a chromosome 13q-deletion," Leukemia, vol. 21, no. 1, pp. 164-168, 2007.

[60] L. Lodé, M. Eveillard, V. Trichet et al., "Mutations in TP53 are exclusively associated with del(17p) in multiple myeloma," Haematologica, vol. 95, no. 11, pp. 1973-1976, 2010.

[61] W. Xiong, X. Wu, S. Starnes et al., "An analysis of the clinical and biologic significance of TP53 loss and the identification of potential novel transcriptional targets of TP53 in multiple myeloma," Blood, vol. 112, no. 10, pp. 4235-4246, 2008.

[62] J. Drach, J. Ackermann, E. Fritz et al., "Presence of a p53 gene deletion in patients with multiple myeloma predicts for short survival after conventional-dose chemotherapy," Blood, vol. 92, no. 3, pp. 802-809, 1998.

[63] B. Lucani, G. Papini, M. Bocchia, and A. Gozzetti, "P53 and molecular genetics of multiple myeloma," Journal of Blood Disorders, vol. 1, no. 1, p. 3, 2014.

[64] A. D. Panani, A. D. Ferti, C. Papaxoinis, S. A. Raptis, and C. Roussos, "Cytogenetic data as a prognostic factor in multiple myeloma patients: involvement of $1 \mathrm{p} 12$ region an adverse prognostic factor," Anticancer Research, vol. 24, no. 6, pp. 41414146, 2004.

[65] Y. Marzin, D. Jamet, N. Douet-Guilbert et al., "Chromosome 1 abnormalities in multiple myeloma," Anticancer Research, vol. 26, no. 2, pp. 953-959, 2006.

[66] M. H. Qazilbash, R. M. Saliba, B. Ahmed et al., "Deletion of the short arm of chromosome 1 (del lp) is a strong predictor of poor outcome in myeloma patients undergoing an autotransplant," Biology of Blood and Marrow Transplantation, vol. 13, no. 9, pp. 1066-1072, 2007.

[67] S. Caltagirone, M. Ruggeri, S. Aschero et al., "Chromosome 1 abnormalities in elderly patients with newly diagnosed multiple myeloma treated with novel therapies," Haematologica, vol. 99, no. 10, pp. 1611-1617, 2014.

[68] F. Zhan, J. Hardin, B. Kordsmeier et al., "Global gene expression profiling of multiple myeloma, monoclonal gammopathy of undetermined significance, and normal bone marrow plasma cells," Blood, vol. 99, no. 5, pp. 1745-1757, 2002.

[69] F. Zhan, Y. Huang, S. Colla et al., "The molecular classification of multiple myeloma," Blood, vol. 108, no. 6, pp. 2020-2028, 2006.

[70] A. Broyl, D. Hose, H. Lokhorst et al., "Gene expression profiling for molecular classification of multiple myeloma in newly diagnosed patients," Blood, vol. 116, no. 14, pp. 2543-2553, 2010.

[71] W. J. Chng, S. Kumar, S. VanWier et al., "Molecular dissection of hyperdiploid multiple myeloma by gene expression profiling," Cancer Research, vol. 67, no. 7, pp. 2982-2989, 2007.

[72] O. Decaux, L. Lodé, F. Magrangeas et al., "Prediction of survival in multiple myeloma based on gene expression profiles reveals cell cycle and chromosomal instability signatures in high-risk patients and hyperdiploid signatures in low-risk patients: a study of the Intergroupe Francophone du Myélome," Journal of Clinical Oncology, vol. 26, no. 29, pp. 4798-4805, 2008.
[73] R. Kuiper, A. Broyl, Y. De Knegt et al., "A gene expression signature for high-risk multiple myeloma," Leukemia, vol. 26, no. 11, pp. 2406-2413, 2012.

[74] R. Kuiper, M. Van Duin, M. H. Van Vliet et al., "Prediction of high- and low-risk multiple myeloma based on gene expression and the international staging system," Blood, vol. 126, no. 17, pp. 1996-2004, 2015.

[75] M. Dimopoulos, R. Kyle, J. P. Fermand et al., "Consensus recommendations for standard investigative workup: report of the International Myeloma Workshop Consensus Panel 3," Blood, vol. 117, no. 18, pp. 4701-4705, 2011.

[76] S. V. Rajkumar, R. A. Kyle, T. M. Therneau et al., "Serum free light chain ratio is an independent risk factor for progression in monoclonal gammopathy of undetermined significance," Blood, vol. 106, no. 3, pp. 812-817, 2005.

[77] J. T. Larsen, S. K. Kumar, A. Dispenzieri, R. A. Kyle, J. A. Katzmann, and S. V. Rajkumar, "Serum free light chain ratio as a biomarker for high-risk smoldering multiple myeloma," Leukemia, vol. 27, no. 4, pp. 941-946, 2013.

[78] D. Dingli, R. A. Kyle, S. V. Rajkumar et al., "Immunoglobulin free light chains and solitary plasmacytoma of bone," Blood, vol. 108, no. 6, pp. 1979-1983, 2006.

[79] S. Jagannath, "Value of serum free light chain testing for the diagnosis and monitoring of monoclonal gammopathies in hematology," Clinical Lymphoma and Myeloma, vol. 7, no. 8, pp. 518-523, 2007.

[80] M. Kraj, "Immunoglobulin heavy chain/light chain pairs (Hlc, Hevylite $^{\mathrm{TM}}$ ) assays for diagnosing and monitoring monoclonal gammopathies," Advances in Clinical and Experimental Medicine, vol. 23, no. 1, pp. 127-133, 2014.

[81] E. Koulieris, P. Panayiotidis, S. J. Harding et al., "Ratio of involved/uninvolved immunoglobulin quantification by Hevylite $^{\mathrm{TM}}$ assay: clinical and prognostic impact in multiple myeloma," Experimental Hematology \& Oncology, vol. 1, no. 9, 2012.

[82] F. E. Lecouvet, B. C. Vande Berg, J. Malghem, and B. E. Maldague, "Magnetic resonance and computed tomography imaging in multiple myeloma," Seminars in Musculoskeletal Radiology, vol. 5, no. 1, pp. 43-56, 2001.

[83] National Comprehensive Cancer Network (NCCN), Clinical Practice Guidelines in Oncology, Multiple myeloma, V.1.2016.

[84] A. Baur-Melnyk, S. Buhmann, H. R. Dürr, and M. Reiser, "Role of MRI for the diagnosis and prognosis of multiple myeloma," European Journal of Radiology, vol. 55, no. 1, pp. 56-63, 2005.

[85] M. A. Dimopoulos, J. Hillengass, S. Usmani et al., "The role of magnetic resonance imaging in the management of patients with multiple myeloma: a consensus statement on behalf of the international myeloma working group," Journal of Clinical Oncology, vol. 33, no. 6, pp. 657-664, 2015.

[86] M. A. Bredella, L. Steinbach, G. Caputo, G. Segall, and R. Hawkins, "Value of FDG PET in the assessment of patients with multiple myeloma," American Journal of Roentgenology, vol. 184, no. 4, pp. 1199-1204, 2005.

[87] P. Moreau, "PET-CT in MM: a new definition of CR," Blood, vol. 118, no. 23, pp. 5984-5985, 2011.

[88] E. Terpos, M. Kleber, M. Engelhardt et al., "European myeloma network guidelines for the management of multiple myelomarelated complications," Haematologica, vol. 100, no. 10, pp. 12541266, 2015. 
[89] M. J. Pianko, E. Terpos, G. D. Roodman et al., "Whole-body low-dose computed tomography and advanced imaging techniques for multiple myeloma bone disease," Clinical Cancer Research, vol. 20, no. 23, pp. 5888-5897, 2014.

[90] G. S. Nowakowski, T. E. Witzig, D. Dingli et al., "Circulating plasma cells detected by flow cytometry as a predictor of survival in 302 patients with newly diagnosed multiple myeloma," Blood, vol. 106, no. 7, pp. 2276-2279, 2005.

[91] P. R. Greipp, T. Leong, J. M. Bennett et al., "Plasmablastic morphology - an independent prognostic factor with clinical and laboratory correlates: eastern Cooperative Oncology Group (ECOG) myeloma trial E9486 report by the ECOG myeloma laboratory group," Blood, vol. 91, no. 7, pp. 2501-2507, 1998.

[92] W. J. Chng, A. Dispenzieri, C.-S. Chim et al., "IMWG consensus on risk stratification in multiple myeloma," Leukemia, vol. 28, no. 2, pp. 269-277, 2014.

[93] F. Gay, A. Larocca, P. Wijermans et al., "Complete response correlates with long-term progression-free and overall survival in elderly myeloma treated with novel agents: analysis of 1175 patients," Blood, vol. 117, no. 11, pp. 3025-3031, 2011.

[94] J. J. Lahuerta, M. V. Mateos, J. Martínez-López et al., "Influence of pre- and post-transplantation responses on outcome of patients with multiple myeloma: sequential improvement of response and achievement of complete response are associated with longer survival," Journal of Clinical Oncology, vol. 26, no. 35, pp. 5775-5782, 2008.

[95] B. G. Durie, J. L. Harousseau, J. S. Miguel et al., "International uniform response criteria for multiple myeloma," Leukemia, vol. 20, no. 9, pp. 1467-1473, 2006.

[96] S. Vincent Rajkumar, J.-L. Harousseau, B. Durie et al., “Consensus recommendations for the uniform reporting of clinical trials: report of the International Myeloma Workshop Consensus Panel 1," Blood, vol. 117, no. 18, pp. 4691-4695, 2011.

[97] B. Paiva, J. J. M. Van Dongen, and A. Orfao, "New criteria for response assessment: role of minimal residual disease in multiple myeloma," Blood, vol. 125, no. 20, pp. 3059-3068, 2015.

[98] J. F. S. San Miguel, J. Almeida, G. Mateo et al., "Immunophenotypic evaluation of the plasma cell compartment in multiple myeloma: a tool for comparing the efficacy of different treatment strategies and predicting outcome," Blood, vol. 99, no. 5, pp. 1853-1856, 2002.

[99] B. Paiva, M. B. Vidriales, J. Cerveró et al., "Multiparameter flow cytometric remission is the most relevant prognostic factor for multiple myeloma patients who undergo autologous stem cell transplantation," Blood, vol. 112, no. 10, pp. 4017-4023, 2008.

[100] N. Puig, M. E. Sarasquete, A. Balanzategui et al., "Critical evaluation of ASO RQ-PCR for minimal residual disease evaluation in multiple myeloma. A comparative analysis with flow cytometry," Leukemia, vol. 28, no. 2, pp. 391-397, 2014.

[101] J. Martinez-Lopez, J. J. Lahuerta, F. Pepin et al., "Prognostic value of deep sequencing method for minimal residual disease detection in multiple myeloma," Blood, vol. 123, no. 20, pp. 3073-3079, 2014.

[102] J. Bladé, C. Fernández de Larrea, L. Rosiñol, M. T. Cibeira, R. Jiménez, and R. Powles, "Soft-tissue plasmacytomas in multiple myeloma: incidence, mechanisms of extramedullary spread, and treatment approach," Journal of Clinical Oncology, vol. 29, no. 28, pp. 3805-3812, 2011.

[103] J. Hillengass, T. Bäuerle, R. Bartl et al., "Diffusion-weighted imaging for non-invasive and quantitative monitoring of bone marrow infiltration in patients with monoclonal plasma cell disease: a comparative study with histology," British Journal of Haematology, vol. 153, no. 6, pp. 721-728, 2011.

[104] B. Paiva, M. B. Vidriales, J. Cerveró et al., "Multiparameter flow cytometric remission is the most relevant prognostic factor for multiple myeloma patients who undergo autologous stem cell transplantation," Blood, vol. 112, no. 10, pp. 4017-4023, 2008.

[105] A. C. Rawstron, J. A. Child, R. M. de Tute et al., "Minimal residual disease assessed by multiparameter flow cytometry in multiple myeloma: impact on outcome in the Medical Research Council Myeloma IX Study, Journal of Clinical Oncology, vol. 31, no. 20, pp. 2540-2547, 2013.

[106] M. E. Gore, C. Viner, M. Meldrum et al., "Intensive treatment of multiple myeloma and criteria for complete remission," The Lancet, vol. 334, no. 8668, pp. 879-882, 1989.

[107] J. Bladé, D. Samson, D. Reece et al., "Criteria for evaluating disease response and progression in patients with multiple myeloma treated by high-dose therapy and haemopoietic stem cell transplantation," British Journal of Haematology, vol. 102, no. 5, pp. 1115-1123, 1998.

[108] B. G. Durie, J. L. Harousseau, J. S. San Miguel et al., "International uniform response criteria for multiple myeloma," Leukemia, vol. 20, no. 9, pp. 1467-1473, 2006. 


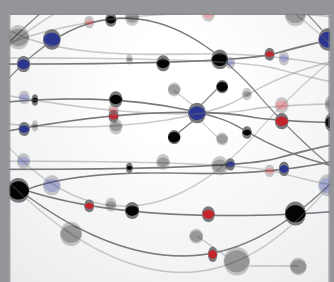

The Scientific World Journal
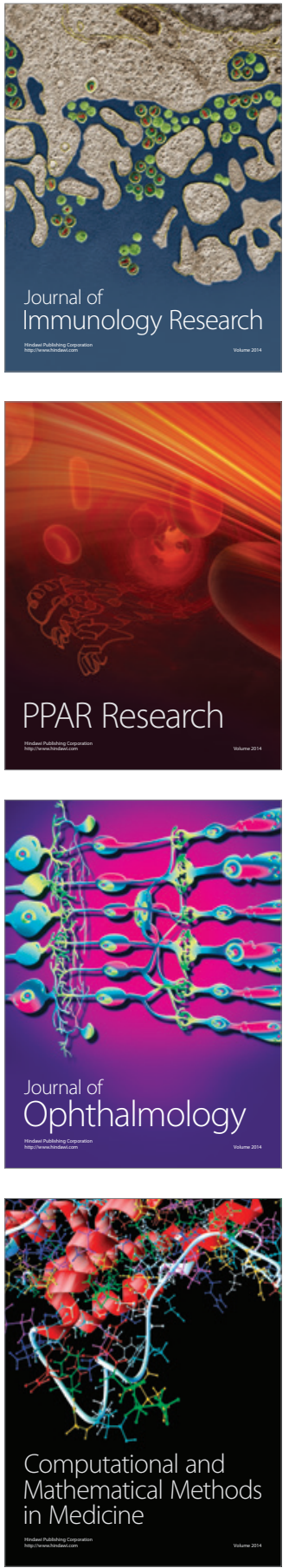

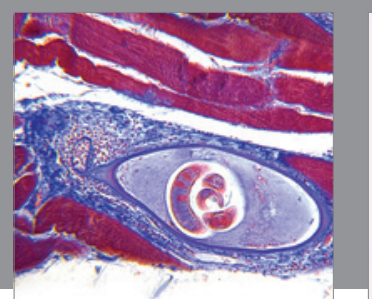

Gastroenterology Research and Practice
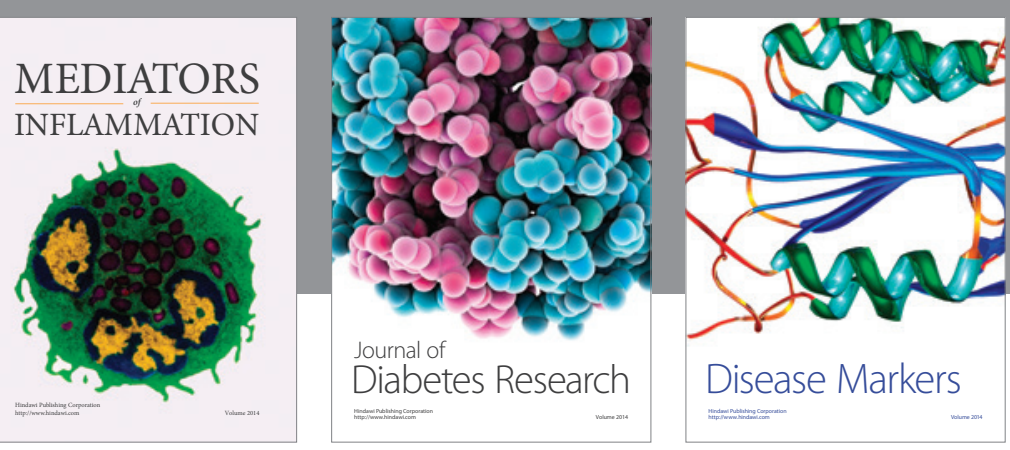

Disease Markers

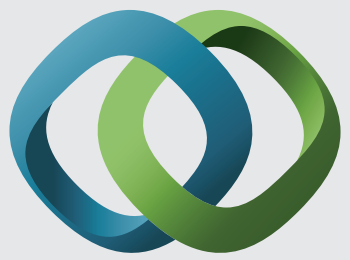

\section{Hindawi}

Submit your manuscripts at

https://www.hindawi.com
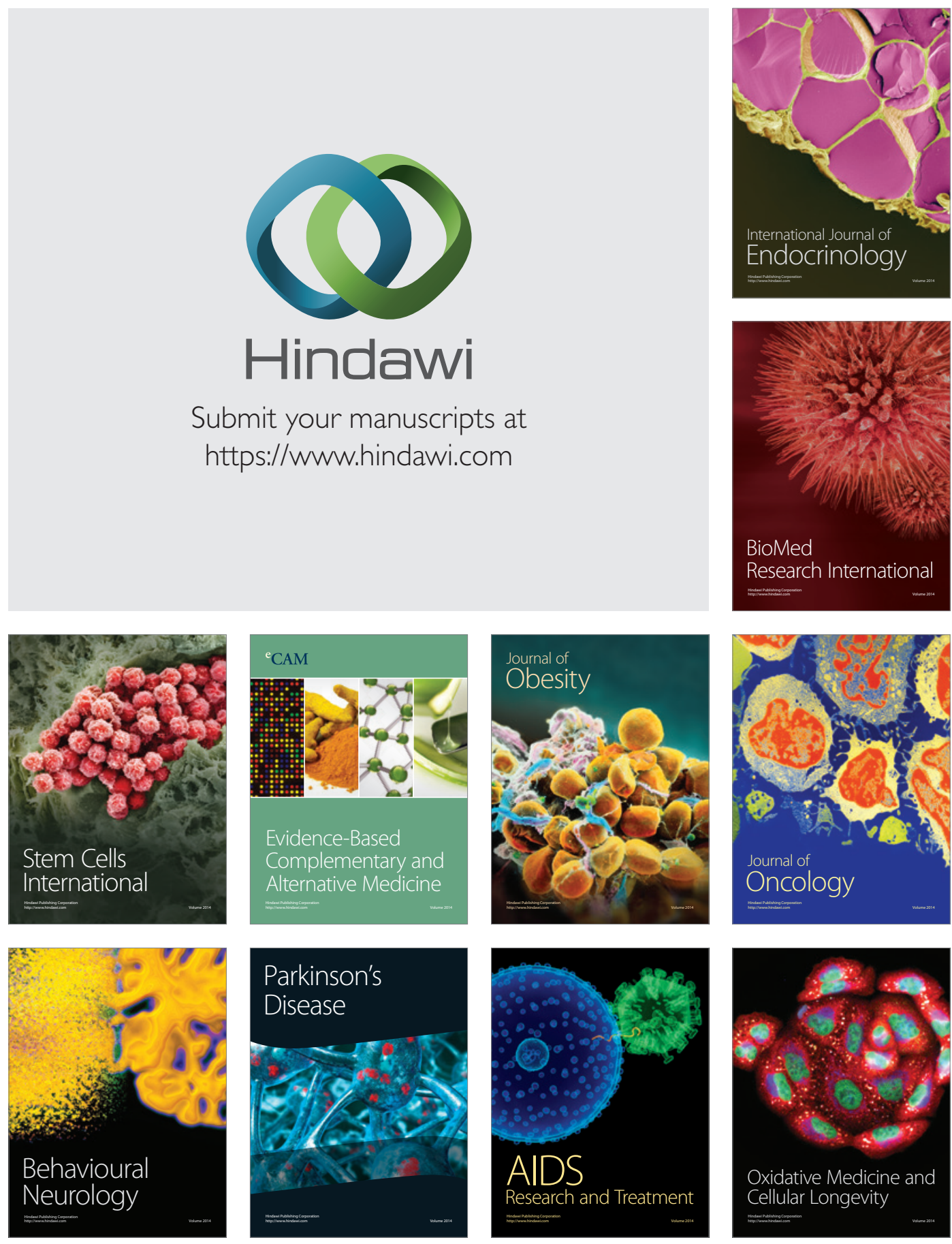